\title{
Muito além dos pixels: experiências de consumo e cultura material em League of Legends
}

\section{Far beyond the pixels: consumption and material culture experiences in League of Legends}

\author{
Tarcízio Macedo ${ }^{1}$ \\ Manuela do Corral Vieira ${ }^{2}$
}

Resumo: Este artigo procura discutir as práticas de consumo no jogo digital League of Legends (LoL) a partir de um olhar baseado nos estudos do campo da comunicação e da cultura material. O objetivo é compreender a relação entre objetos e jogadores-sujeitos-consumidores. Para tanto, procuramos analisar a trajetória social e cultural dessas mercadorias nas experiências simbólicas em LoL. Nessa perspectiva, e fazendo uso de método etnográfico, são apresentados relatos e observações do consumo de objetos em LoL por jogadores das cidades de Belém (PA), Diadema (SP) e Osasco (SP). Os resultados apontam para a existência de uma complexa teia de significados interconectados responsáveis por (de)codificar os objetos e transformar aglomerados de pixels em experiências de comunicação, consumo e cultura material.

Palavras-chave: jogos digitais; consumo; cultura material; bens virtuais; comunicação.

Abstract: This article seeks to discuss consumer practices in the digital game League of Legends (LoL), from a study based on the field of communication and material culture. The objective is to understand the relationship between objects and players-subjects-consumers. In order to do so, we seek to analyze the social and cultural trajectory of these commodities in the symbolic experiences in LoL. In this perspective, according to the ethnographic method, reports and

1 Universidade Federal do Pará. Belém, PA, Brasil. E-mail: tarcizio.macedo@bol.com.br

2 Universidade Federal do Pará. Belém, PA, Brasil. E-mail: manuelacorralv@yahoo.com.br 
observations of the consumption of objects in LoL are presented by players from the cities of Belém (PA), Diadema (SP) and Osasco (SP). The results point to the existence of a complex web of interconnected meanings, responsible for (de)codify the objects and transform aggregations of pixels into experiences of communication, consumption and material culture.

Keywords: digital games; consumption; material culture; virtual goods; communication. 


\section{Introdução}

Esta pesquisa busca analisar o consumo do que chamamos de "bens virtuais"3 no jogo em ambiente digital League of Legends (conhecido popularmente como League ou LoL). A proposta é compreender os modos de consumir mercadorias digitais, presentes nesse jogo on-line, a partir de uma abordagem baseada nos estudos do consumo e embasada nas categorias do simbólico, das dinâmicas dos valores, das relações sociais e da cultura material que mercadorias consumíveis no ambiente de LoL podem promover em interação com os sujeitos. O que se pretende é capturar como esses objetos ${ }^{4}$ em jogo são situados simbolicamente, como são interpretados e "manipulados" por meio dos símbolos que evocam e do desempenho individual que assumem em contextos variados de League.

Analisam-se, assim, como questões envolvendo valores e significados do uso de determinados objetos são elementos fundamentais dentro do consumo que se desenvolve em/no jogo e como experiências e valores são acionados e incidem nas dinâmicas do consumo de bens virtuais em LoL. Trata-se de compreender o lugar no mundo dos objetos em League na relação entre jogadores, procurando entender a vida social dessas "coisas".

Nesse sentido, entre inúmeras atividades de entretenimento e diferentes tipos de jogos que se desenvolveram ao longo dos anos, os jogos digitais mostram-se na vanguarda da chamada indústria do entretenimento. Entre os mais diversos tipos de jogos da atualidade, debruçamo-nos sobre um específico: League of Legends, um jogo gratuito on-line exclusivo para computadores. A escolha desse jogo se deu tanto por questões que envolvem o Brasil e a região Amazônica de forma representacional em LoL (cf. MACEDO e AMARAL FILHO, 2015) quanto pela popularidade e inserção nacional nesse ambiente.

3 Segundo Jens Frieling (2013) e Jennifer Martin (2008), bens virtuais são itens que existem exclusivamente em ambientes digitais, mas são adquiridos com dinheiro real. Aprofundaremos a conceituação do termo posteriormente.

4 Objeto é compreendido neste estudo, tal como argumenta Ian Woodward (2007, p. 3), como “coisas materiais que as pessoas encontram, interagem e usam” (tradução nossa). 
O jogo em questão foi criado pela desenvolvedora norte-americana Riot Games, com sede em Los Angeles (EUA) e 13 escritórios espalhados pelo mundo, um deles na cidade de São Paulo. Segundo a empresa, o alcance global de League ultrapassou a marca de 100 milhões de jogadores ativos mensalmente em 2016. Nesse mesmo ano, LoL liderou o ranking dos jogos on-line mais lucrativos após alcançar US\$ 1,8 bilhão, o equivalente a US $\$ 150$ milhões por mês. ${ }^{5} \mathrm{~A}$ cifra coloca o jogo como o mais rentável do mundo desde 2014.

Para fidelizar milhões de jogadores ativos em um jogo multiusuário em rede, destaca-se a criação de atrativos que mantenham a experiência de jogar em constante ressignificação e motivação. São, portanto, necessários "itens ou elementos formados por pixels que vinculam valores capitais $^{6}$ para a sua aquisição" (REBS, 2012, p. 207), ou seja, mercadorias virtuais que incorporam referências estéticas diversas para atrair o consumidor-jogador. É esse fator relevante de LoL que será o enfoque desta pesquisa e diz respeito ao consumo do que denominamos de "mercadorias virtuais": uma variedade de itens, sejam eles personagens ou adereços dentro do próprio jogo, disponíveis para o jogador por meio de um sistema mercadológico de venda.

$\mathrm{Na}$ economia das mercadorias virtuais, há um comércio formal em League organizado por um sistema blindado pela programação do jogo que regulamenta a aquisição e compra desses itens, exclusivamente processados dentro do ambiente digital. Podemos classificá-los conforme duas grandes categorias que variam em maneiras específicas de aquisição: (i) itens adquiridos in-game a partir da jogabilidade; ${ }^{7}$ (ii) itens

5 Disponível em: https://goo.gl/JL3Ss3 e https://goo.gl/DDdaG4. Acesso em: 15 jan. 2017.

6 Embora exista uma literatura considerável que se dedica aos estudos do consumo e da cultura material utilizando a teoria dos capitais de autores como Pierre Bourdieu, James Coleman e Robert Putnam, cujas contribuições são inegáveis, vale destacar que caminharemos por uma abordagem cultural e simbólica distinta (GELL, 1992; MILLER, 2007, 2013; WOODWARD, 2007).

7 Em jogo, ou seja, itens consumíveis, acessórios para aumentar os atributos dos personagens e melhorar suas performances etc., todos adquiridos por meio de ouro conquistado em consequência da conclusão de determinados objetivos. Essa moeda pode ser trocada por itens em uma loja específica dentro de partidas de LoL.

8 Segundo Katie Salen e Eric Zimmerman (2003), jogabilidade é a interação que ocorre entre jogadores e regras de um sistema formalizado a partir do jogo, ou seja, o ato de jogar. 
obtidos na loja do jogo por meio de Influence Points (IP), ${ }^{9}$ Riot Points (RPs), ${ }^{10}$ via presentes ou por um sistema de recompensas a jogadores que permite criar conteúdos pagos gratuitamente.

Entretanto, este artigo se concentra na segunda categoria, tanto por envolver a aquisição de itens considerados a base do lucro principal da empresa, detentores de maior destaque e divulgação, quanto por abrigar os adereços reconhecidos por todos os interlocutores deste estudo como o motivo primário para compras em League: as chamadas skins, designs customizados com transformações estéticas de personagens dentro do ambiente digital de LoL (Figuras 1 e 2).

Figura 1: Tela de informações da personagem Lux (as skins que ela possui aparecem na parte inferior da imagem $)^{11}$.

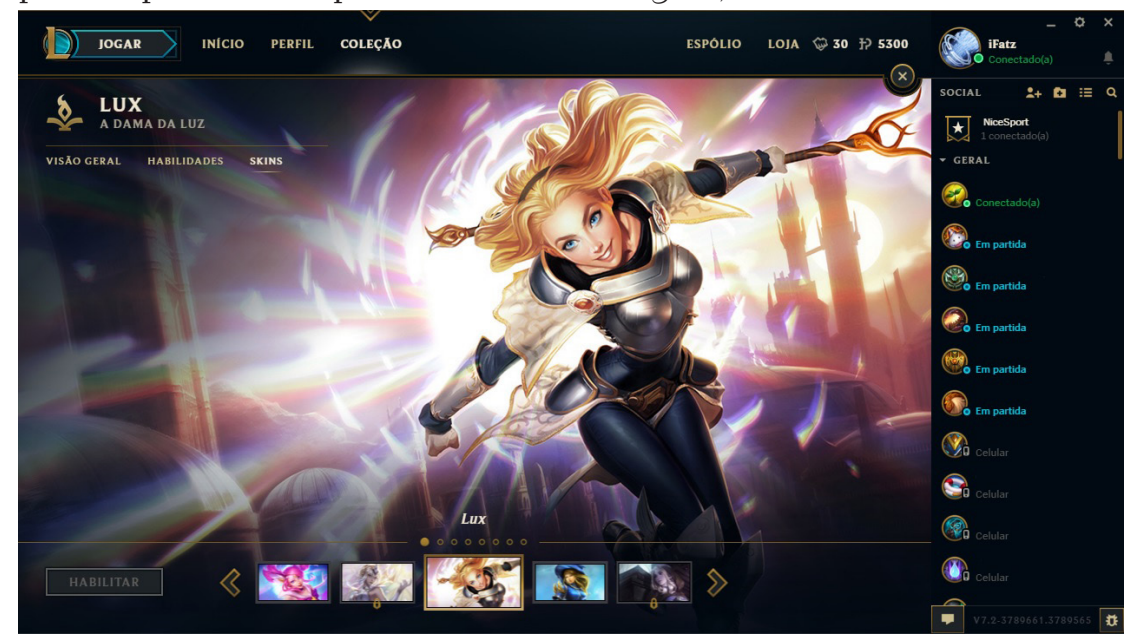

Fonte: Print screen da tela do jogo League of Legends BR.

Essas mercadorias virtuais particulares são liberadas sobretudo, embora não exclusivamente, por meio de RPs, uma espécie de "dinheiro

9 Tratam-se das moedas virtuais existentes em League, uma forma de premiar jogadores por partidas jogadas. São usadas para efetuar trocas, dentro de uma loja do jogo, por personagens, itens para mecânicas, entre outros.

10 Moedas virtuais que precisam ser adquiridas por dinheiro.

11 Foram realizadas intervenções nas imagens, inseridas neste artigo, cujo objetivo foi de preservar as informações dos sujeitos que figuram no jogo e no site de rede social Facebook. 
virtual" que se refere "[...] às moedas circulantes em diferentes jogos que vinculam um valor financeiro simbólico que é usufruído apenas no ambiente virtual" (REBS, 2012, p. 212).

Figura 2: Skin mítica ${ }^{12}$ Lux Elementarista.

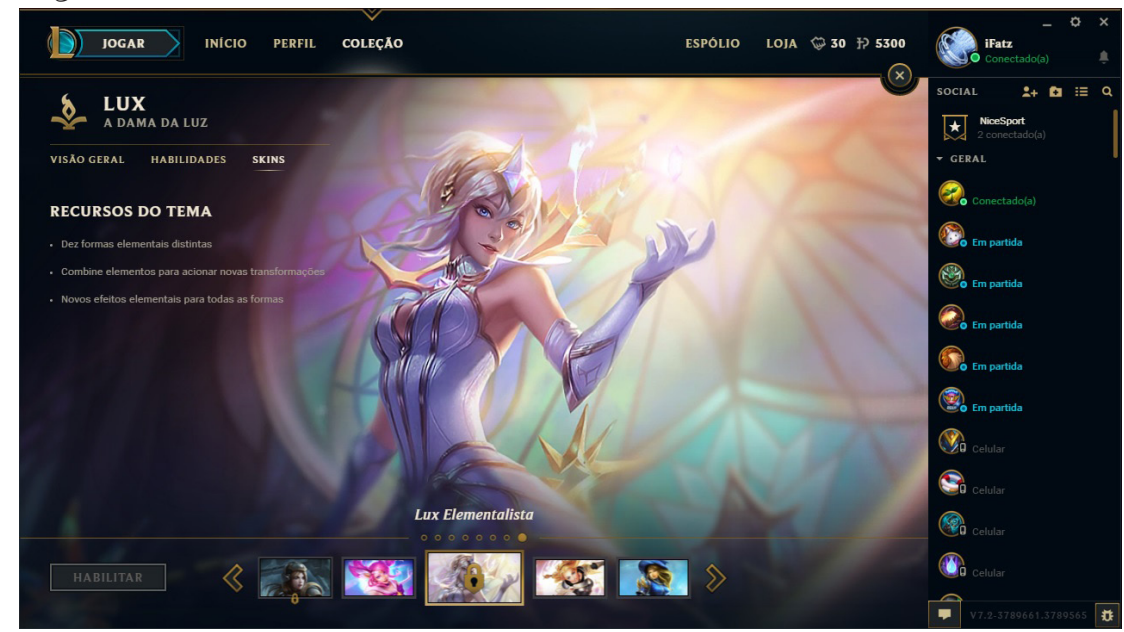

Fonte: Print screen da tela do jogo League of Legends BR.

Este texto está dividido em três seções: na primeira, apresentamos as matrizes metodológicas que sustentam esta investigação com o objetivo de elucidar os pontos de partida da pesquisa; na segunda, alinhavamos questões pontuais sobre as estratégias publicitárias para a promoção de skins em LoL; já a terceira seção abrange, de modo mais específico, a análise que realizamos do consumo de mercadorias virtuais em League a partir dessa cultura material como foco principal do nosso olhar.

\section{Procedimentos metodológicos}

Uma análise do consumo de jogadores em um jogo digital como LoL reivindica do pesquisador especificidades metodológicas que devem se adaptar às peculiaridades características do estudo desse medium, sendo

12 É a skin mais cara presente em LoL e tem o mais alto nível de alterações que esse tipo de item pode alcançar. 
necessário nele agir. Esse é o elemento que compõe o pensamento de Espen Aarseth (2003) ao ressaltar que jogar um videogame, e, portanto, consumi-lo, pressupõe um processo de aprendizagem e a aplicação de uma hermenêutica dinâmica em que o "ir a campo" passa pela necessidade de o pesquisador experimentar o jogo, assumindo a postura de um "usuário-jogador" - logo, engajar-se na experiência materialmente.

Seguindo essa perspectiva, o trabalho de campo neste estudo foi desenvolvido por meio de uma pesquisa etnográfica realizada com sujeitos-jogadores (ou ex-jogadores) de League of Legends que consomem ou já consumiram os mais variados itens disponíveis no jogo a partir de uma abordagem ancorada na cultura material. A escolha dos interlocutores desta pesquisa foi efetivada após uma longa relação baseada na confiança e assiduidade com os jogadores entrevistados, com os quais partilhamos sessões de jogo e aprendemos a explorar o universo de LoL. Destarte, foi justamente essa imersão participativa no campo, durante a própria experiência com os conteúdos existentes no ambiente digital de League, que nos despertou a curiosidade de compreender os modos pelos quais os sujeitos consomem os itens no ambiente de LoL.

Portanto, foram selecionados quatro interlocutores que jogam ou jogaram LoL, cada qual consumindo de distintas maneiras os itens nessa ambiência, três homens e uma mulher (Quadro 1). Todos os participantes tinham conhecimento dos objetivos da pesquisa e os dados obtidos na etnografia, aqui inseridos, estão constituídos por meio de nomes fictícios, escolhidos entre os nomes dos personagens no jogo que cada um afirmava mais jogar ou gostar, no intuito de preservar as identidades dos sujeitos. ${ }^{13}$

A investigação foi guiada com suporte em um roteiro semiestruturado pensado para melhor compreender a relação sobre a dinâmica de LoL e os processos de imersão do consumo, tanto com base nos eixos deste quanto pelas imbricadas percepções advindas de uma pesquisa de campo etnográfica do simbólico, das dinâmicas dos valores, dos

13 Alguns dos nossos interlocutores indicaram preocupação ou já sofreram alguma espécie de assédio moral e/ou sexual ao jogar LoL. Inclusive, o assédio neste jogo digital é um dos motivos responsáveis por uma jogadora decidir parar de jogá-lo. 
relacionamentos sociais e dos imaginários que mercadorias consumíveis no jogo carregam. Não se trata, contudo, apenas de uma questão que envolve sujeitos "ponderando o que os objetos podem significar" (WOODWARD, 2007, p. 4), mas, sobretudo, de jogadores interpretando objetos em relação a outros e imersos nas complexas redes intergrupais modeladas pelo papel social e contextos espaço-tempo.

Para se pensar no fenômeno do consumo, segundo expõe Everardo Rocha (2000), é preciso passar pela necessária compreensão da sua conexão intrínseca com a cultura, o que não haveria de ser diferente no ambiente de um jogo on-line. Eis, portanto, a necessidade de acompanhar o universo dos sujeitos no medium a partir da práxis etnográfica e da interação direta com o jogo, o que pressupõe uma passagem pela dinâmica de jogá-lo (AARSETH, 2003) e de perceber como atuam os códigos culturais que dão coerência às práticas. Nesse sentido, a pesquisa de campo se deu entre junho de 2016 e janeiro de 2017 com jogadores em uma faixa etária dos 18 aos 26 anos.

Quadro 1. Interlocutores do estudo.

\begin{tabular}{|c|c|c|c|}
\hline Jogador(a) & Idade & Tempo de LoL & Cidade \\
\hline Lulu & 23 anos & Joga há dois anos. & Belém/PA \\
\hline Jinx & 22 anos & $\begin{array}{l}\text { Jogou durante dois anos, parou há } \\
\text { quatro meses. }\end{array}$ & Belém/PA \\
\hline Talon & 26 anos & Joga há três anos. & Diadema/SP \\
\hline Draven & 18 anos & Joga há três anos e meio. & Osasco/SP \\
\hline
\end{tabular}
Fonte: Os autores.

Elaborado em duas etapas, o trabalho de campo ocorreu da seguinte forma: inicialmente, para contato com possíveis interlocutores, fizemos uso de um perfil em LoL e efetuamos buscas em grupos relacionados ao jogo no site de rede social Facebook. Posteriormente, realizamos entrevistas semiestruturadas entre os meses de dezembro de 2016 e janeiro de 2017: presencialmente, com dois jogadores em Belém (PA), e via chamada de vídeo pelo aplicativo Skype, com sujeitos das cidades de Osasco (SP) e Diadema (SP). 
Logo, esta pesquisa se enquadra em uma abordagem etnográfica on e off-line indicada por Daniel Miller e Don Slater (2004). O campo, portanto, tem uma dinâmica em rede, característica do próprio objeto de estudo. Na seção seguinte, nossa reflexão se concentra em discorrer, brevemente, sobre as estratégias publicitárias utilizadas pela empresa do jogo na promoção de mercadorias virtuais.

\section{Estratégias publicitárias para a promoção de mercadorias virtuais em LoL}

Segundo argumentam Everardo Rocha, Carla Barros e Karine Karam (2014), o entretenimento e o consumo são práticas relacionadas em vários planos, apesar de diversão nem sempre ser sinônimo de consumo. Nessa perspectiva, seguindo o pensamento dos autores, ambos os fenômenos têm uma relação de relevante análise, apta a evidenciar e melhor compreender pertencimentos, gostos de grupos sociais ou sujeitos, estilos, além de distinções sancionadas e legitimadas socialmente.

No Brasil, de acordo com estimativas da Newzoo, ${ }^{14}$ o mercado de jogos gerará receita de US\$1,3 bilhão em 2017, dado que o mantém como líder do gênero na América do Sul e o $13^{\circ}$ no mundo. Isso inclui todos os tipos de jogos, dos mais simples, disponíveis em navegadores e smartphones, até os mais complexos, para consoles e computadores. Segundo a pesquisa da Newzoo de 2017, 66,3 milhões de brasileiros jogam algum videogame; já um relatório de $2015^{15}$ indica que $56 \%$ dos 33,6 milhões de jogadores gastaram com algum tipo de jogo, em média, US\$ 43,54 por ano, dado considerado maior do que a média para a região, avaliada em US\$37. Em território nacional, a Pesquisa Game Brasil 2017,16 realizada pela Sioux, Blend New Research e pela Escola Superior de Propaganda e Marketing (ESPM) com 2.947 entrevistados, indicou que 58,7\% destes costumam jogar algum tipo de jogo on-line. A segunda plataforma mais popular é o computador, com $66,4 \%$. A

\footnotetext{
14 Disponível em: https://goo.gl/UPmPdD. Acesso em: 24 set. 2017.

15 Disponível em: https://goo.gl/uAyy9Z. Acesso em: 15 jan. 2017.

16 Disponível em: https://goo.gl/rjYo5q. Acesso em: 24 set. 2017.
} 
maioria do público de jogadores brasileiros tem de 25 a 34 anos, compreendendo 53,6\% dos declarantes mulheres e 46,4\% homens.

Nesse cenário, uma série de ações realizadas pela empesa Riot Games para criação de mercadorias virtuais, como skins e campeões (personagens do jogo), incluem a disseminação de peças publicitárias (carregadas de conteúdos e informações) em múltiplas plataformas de mídia graças à convergência midiática (MACEDO e AMARAL FILHO, 2015), desde a produção de vídeos promocionais, histórias em quadrinhos, audionovelas, álbuns de músicas (Figura 3), contos sobre personagens, eventos especiais, promoções de itens periodicamente, quizzes, aplicativos para smartphones, contratação de bandas famosas para composição de músicas $^{17}$ etc. Cada uma dessas estratégias tem impacto na experiência de consumo do jogador e, muito provavelmente, em suas escolhas no ato de compra de determinadas mercadorias virtuais.

É, então, por meio de um sistema simbólico formado pelos meios de comunicação utilizados pela desenvolvedora de LoL, como seu site oficial, fóruns e suas redes sociais na internet (Figura 4), que grande parte dos atos de consumo são estimulados. Acerca das mercadorias que são objeto desta pesquisa, diferentes tipos de skins utilizam distintos níveis de mensagens; portanto, quanto mais valor tem um item, maior será a quantidade de peças publicitárias que ajudarão a veiculá-lo no ambiente narrativo que compõe o jogo.

Pela via da inserção dessas estratégias, a Riot Games torna possível o consumo de mercadorias virtuais que não oferecem nenhuma vantagem em atributos ou bônus no jogo, diferentemente de outros jogos digitais nos quais a maioria dos itens disponíveis à venda fornecem melhorias ao jogador. Assim, a empresa transforma "matéria inerte em cultura material” (ROCHA, 2000, p. 26, grifo do autor). Como algumas das etapas desse processo são efetivadas a partir das apropriações dos jogadores é o pretendemos aprofundar na seção seguinte.

17 O grupo estadunidense Imagine Dragons foi contratado pela Riot Games em 2014 para composição da música tema "Warriors" do World Championship. Disponível em: https:/goo.gl/ SgblY2. Acesso em: 11 fev. 2017. 
Figura 3: Álbum de músicas Smite and Ignite para o lançamento do conjunto de skins temáticas Pentakill.

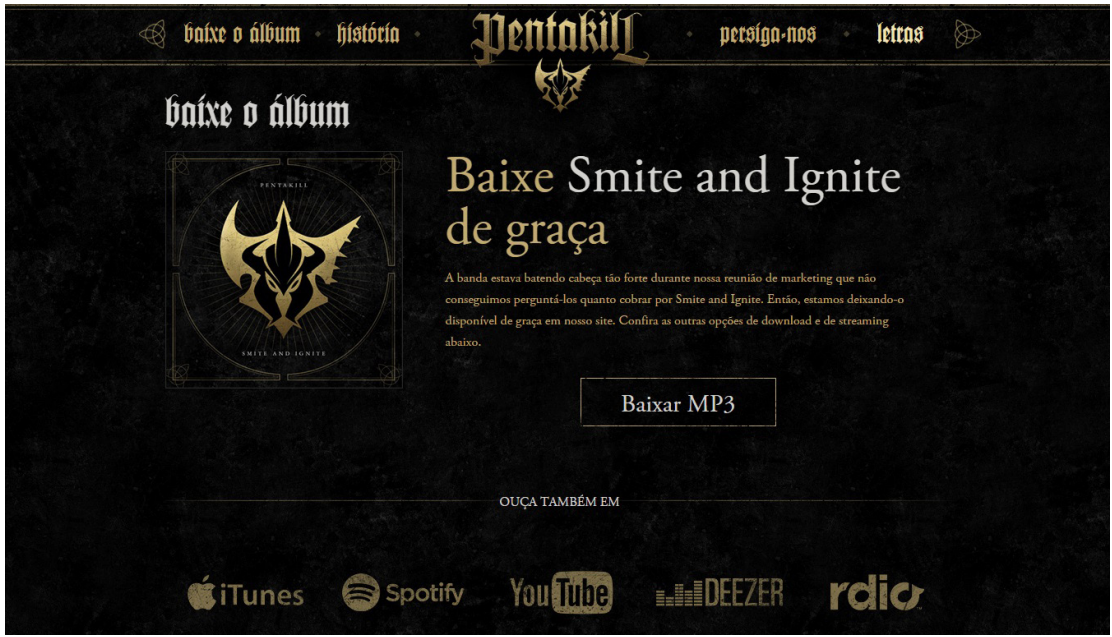

Fonte: Print screen da página Penta Kill Music. Disponível em: https://goo.gl/DlJTzH. Acesso em: 11 fev. 2017

Figura 4: Página no Facebook de LoL divulgando uma peça para o lançamento da skin Lux Elementarista.

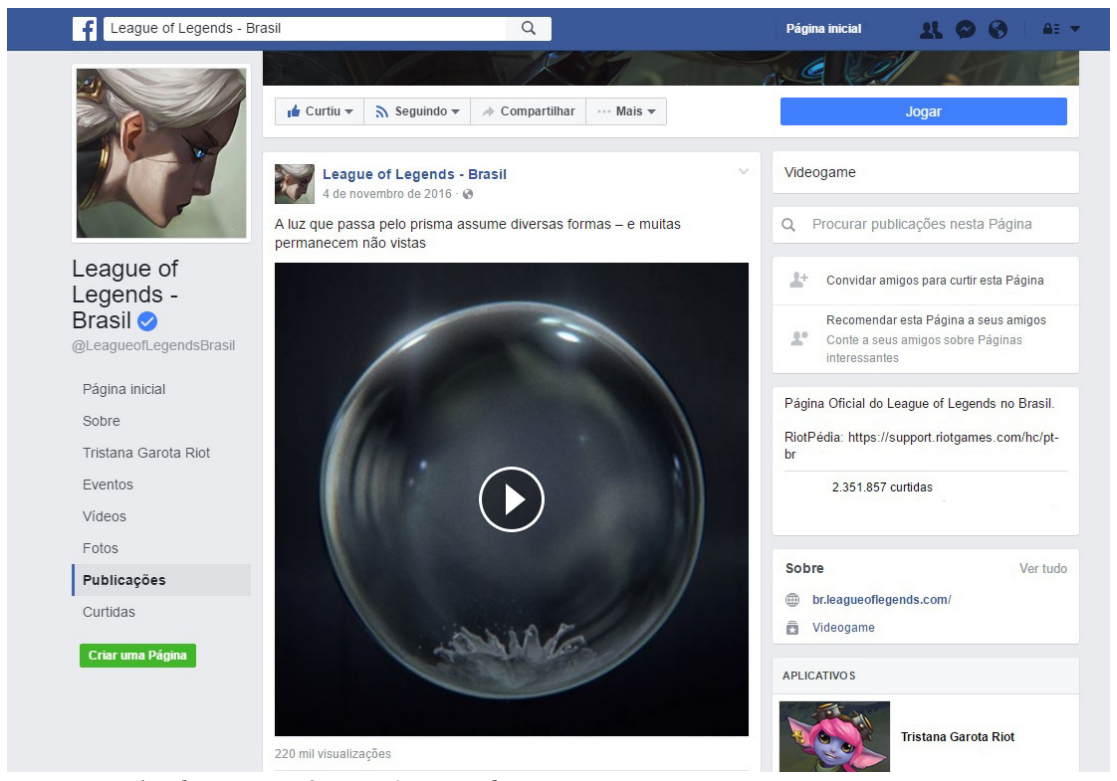

Fonte: Facebook League of Legends - Brasil. 


\section{Objetos em jogo: cultura material e simbólica nas práticas de consumo em League of Legends}

Objetos fazem parte da nossa vida cotidiana e, a todo instante, a existência diária é marcada por encontros com eles. Ian Woodward (2007) enfatiza como objetos, aparentemente inanimados, atuam sobre os sujeitos e são atuados por estes com a finalidade de desempenhar funções sociais, proporcionar sentidos simbólicos às práticas humanas, regulamentar as dinâmicas sociais e transportar valores culturais. Objetos são imbuídos, portanto, da capacidade de significar e simbolizar coisas ou mesmo estabelecer significações sociais em nome de pessoas e grupos.

Nessa perspectiva, cada episódio de consumo é também um ato de comunicação simultâneo, porque as escolhas dos sujeitos, os modos como se organizam e dão sentido aos espaços cotidianos criam significados e promovem circuitos simbólicos que ultrapassam a materialidade do consumo, alcançando a esfera das ideias e representações, representante de um modo de viver, um estilo de vida, superando em significação o consumo material (CASTRO, 2014).

Daniel Miller (2007) argumenta que os estudos de cultura material procuram uma compreensão intensa da relação humana inseparável da materialidade que a ronda, da preocupação entre as conexões mútuas entre objetos e pessoas. A partir desse aporte, consideramos bens enquanto objetos repletos de simbolismos que, em interação, podem ser capazes de promover expressões e representações, bem como desdobramentos de experiências e significações. São, assim, elementos que têm valores que constituem realidades com múltiplas faces, desde seus significados enquanto mercadorias (valor mercantil) até sua importância de significações (valor sociocultural). Para Woodward (2007), bens são objetos produzidos no domínio das relações específicas de mercado, nas quais são atribuídos valores dentro de um sistema de troca. Mercadoria, por sua vez, trata-se de uma expressão técnica diretamente associada ao conceito de "bem", do mesmo modo podendo ser trocada.

Seguindo essa abordagem, o consumo passa a ser visto como um processo de envolvimento com as mercadorias (objetos em jogo, no caso de 
LoL) que incidem, simultaneamente, na prática e na construção de sentidos, oferecendo formas, modos de condutas e entendimentos a serem empregados na relação com objetos e sujeitos. Essa questão pode ser percebida na fala da jogadora Jinx, uma das interlocutoras deste estudo, que, mesmo sem classificar a observação como proveniente da cultura material entre pessoas e objetos, destaca marcas dessa relação ao comentar sobre a relevância ou indiferença de se ter uma skin em League:

Eu não diria que ela é importante ou indiferente, porque ela nunca vai ser indiferente, eu acho que ela sempre vai ter um significado pra quem compra e um significado pra quem tá vendo, que a pessoa tem uma skin (Jinx, em entrevista aos pesquisadores).

O que se revela e evidencia na fala de Jinx é a complexidade de LoL, o quanto jogar implica uma dependência dos objetivos de quem joga, dos significados, das observações que se compreende, das experiências que se pretende alcançar e vivenciar, das maneiras como se age perante os demais.

No caso dos jogos de plataformas digitais, "bens virtuais", em um sentido bastante estrito, são objetos digitais, moedas e outros conteúdos premiums (pagos) que somente existem em jogos digitais e em alguns sites de redes sociais (FRIELING, 2013). Dessa forma, as apropriações e os usos interativos desses produtos dependerá das dinâmicas desses ambientes particulares e seus gêneros específicos, desde aspectos funcionais, decorativos até simbólicos. Frieling (2013) afirma que o aumento do comércio de bens virtuais amplia diversos ensejos de pesquisa e levanta questões fundamentais, como compreender os motivos pelos quais os consumidores estão dispostos a comprar essas mercadorias. Segundo Rebeca Rebs (2012), baseada em Mike Featherstone (1995), as motivações para o consumo desses objetos costumam indicar necessidades de compras típicas dos bens de consumo materiais, coincidindo em práticas de compra, posse, venda e troca de produtos em um mercado de bens de entretenimento formados por pixels que perpassam por questões de significados imateriais. Podemos perceber, na fala de Talon, 
dinâmicas próximas das apontadas pelo estudo de Rebs (2012), bem como sobre as questões levantadas:

É tipo como comprar roupa de marca, é igual quando você tem aquele tênis de mil reais [risos], os outros olham pra você: "pô, você tá com um Adidas de "milzão' aí no pé" [...] (Talon, em entrevista aos pesquisadores).

Notemos, portanto, que assim como as roupas para Miller (2013), podemos pensar nas skins como algo que faz dos jogadores o que pensam ser. Significa considerar que elas vestem os sujeitos, como as skins fazem deles o que são, que tais objetos também agem sobre os jogadores. Em League of Legends, como já dissemos, elas não alteram ou fortalecem atributos e habilidades dos personagens, que permanecem os mesmos. Por meio da pesquisa de campo, foi possível constatar que grande parte dos interlocutores busca atingir uma experiência melhor dentro do ambiente digital do jogo mediante a aquisição de bens on-line (MARTIN, 2008), conforme percebemos no registro de Draven:

Compro muita skin [...], acho que é porque dá uma animada mais no jogo, tipo, você chegar na partida e o pessoal falar: "nossa, que skin maneira, que skin louca!”. Alguém falar pra você dá até uma satisfação maior, dá até mais uma animada, você joga até com mais vontade, querer honrar a skin, honrar o campeão que você joga (Draven, em entrevista aos pesquisadores).

Para Draven, os valores das skins obtêm sentidos advindos de diferentes significantes, entre os quais figuram: prestígio e reconhecimento a partir da visibilidade desses objetos com consequente animação e satisfação pelos seus usos, aumento da vontade de jogar, necessidade de honrar uma skin e um personagem, bem como demonstrar perícia técnica - habilidades e competências - ao utilizá-las in-game (MACEDO e CORRAL VIEIRA, 2017). Ao mesmo tempo, a afirmação de Draven assinala para a cultura material do que Alfred Gell (1992) chamou de uma estética de encantamento ou um "encantamento da tecnologia", responsável por endereçar, em Draven, uma vontade de jogar com campeões que possuam skins. De forma similar, Jinx, ao expressar o que 
costuma privilegiar em um bem virtual, argumentou sua preferência por um tipo de skin que propicia alterações nas dinâmicas dos personagens, porque as transformações estéticas - que essas mercadorias possibilitam para campeões - eram capazes de mudar a visão que ela tinha deles.

Eu gosto de skins que te dão um feeling [sentimento] diferente, por exemplo, têm algumas skins que só mudam a roupinha dele [o personagem] [...], eu gosto de skins que mudem tua percepção acho que dentro do jogo, que não mudem só a roupinha. Porque a roupinha é só, tipo, apesar delas [skins] serem mais baratas, eu não vejo tanto motivo assim pra tu ter (Jinx, em entrevista aos pesquisadores).

Aproximando a perspectiva de Gell (1992) dos estudos de consumo de Featherstone (1995, p. 105), é possível pensar nas skins como propensas a ensejarem um "instantaneamento", ou seja, "o prazer de mergulhar em objetos de contemplação”. Como efeito desse processo, há uma tendência para desenvolverem um "descontrole" das emoções, cujo objetivo é estimular a abertura para todos os tipos de sensações disponíveis que um objeto de consumo pode evocar, do gozo dos prazeres imediatos e físicos até os sensoriais. Destarte, esse encantamento é capaz de propiciar uma sensação de medo e confiança, segundo Lulu e Draven, respectivamente, relatam:

Porque ela [a skin Lux Elementarista, Figura 2] tem um monte de efeitos, todo mundo vai olhar e eu acho que eu causo esse medo, eu posso não saber nada da Lux [Figura 1], mas aí eu tô com a skin e o outro time vai: "égua [regionalismo paraense, interjeição usada para demonstrar espanto]! Ele gastou 40 reais pra comprar essa skin!” É, assim, ou ele é rico demais ou ele lacra [arrasa] com a Lux (Lulu, em entrevista aos pesquisadores).

Acho que outra coisa que as skins ajudam é que te dá um pouco de confiança [...]. Você se sente um pouco exclusivo, superior, isso te dá uma confiança a mais, às vezes pode ajudar no jogo, você se sente mais solto, joga mais na calma, pensa mais pra jogar (Draven, em entrevista aos pesquisadores). 
Pensando na perspectiva da cultura material sobre essa questão, repetidamente (re)caímos em um problema de reificação, isto é, as pessoas costumam imaginar que controlam os objetos, que eles existem simplesmente para que os indivíduos se envolvam ou usem conforme seus próprios termos. Entretanto, a abordagem da cultura material nos mostra que um objeto não pode ser realmente possuído uma vez que transita e interage com diferentes sujeitos e contextos, conferindo a cada um deles uma forma sui generis e independente de valores e significados. Woodward (2007) argumenta que os objetos têm um tipo de poder e agência sobre os indivíduos - ao que Miller (2013) denomina como "objetificação" -, uma "capacidade algo inesperada que os objetos têm de sair do foco, de jazer periféricos à nossa visão e ainda assim determinar o nosso comportamento e a nossa identidade" (MILLER, 2013, p. 79), de tal forma que agem e incutem sobre os jogadores, atribuindo-lhes sentidos e papéis em jogo, não estando passivos ao bel-prazer e "manipulação" por esses sujeitos. Pode-se dizer, portanto, que a skin também faz o jogador em League, ela o veste e faz dele o que é em relação aos outros e com outrem.

Por conseguinte, os jogadores, ao utilizarem objetos como as skins, precisam compreender para além dos usos e práticas que motivam suas compras - a exemplo da experiência estética mencionada pela maioria dos interlocutores. Requer depreenderem, no entanto, essa "vida à parte" independente que não desponta ex nihilo, mas que se desenvolve na criação de skins para que possam navegar mais amplamente no terreno da cultura do jogo. Os jogadores participam do mundo do jogo mediante essa incursão no universo de símbolos coletivos da comunidade de LoL.

Pensar na vida dos objetos em League, em particular aqueles nos quais nos debruçamos, coloca em destaque alguns apontamentos relevantes: as skins, por exemplo, não têm uma forma material específica, exceto por meio de códigos computacionais e pixels. Logo, podemos compreendê-las em decorrência de duas perspectivas: (i) enquanto formadas por camadas de códigos binários e técnicas, portanto, números e elementos de programação, (ii) que chegam ao sujeito a partir de pixels 
pela interface gráfica do computador. Os códigos tendem a ser menos visíveis pelo jogador comum, ao passo que "a estética é o mais visível e perceptível, por representar a interface que é apreendida pelos nossos sentidos" (MACEDO e AMARAL FILHO, 2015, p. 235). Obviamente, uma não existe sem a outra, elas se complementam para formar um todo que chamamos de skin. Ademais, o desempenho em LoL, incluindo seus efeitos, sua composição, suas mudanças nos personagens, suas reparações ao longo dos anos (como em texturas e pigmentações), corresponde a uma outra fase da vida das skins.

Um outro caminho, ou desvio (WOODWARD, 2007), trata de instaurar, por meio das apropriações e dos usos culturais que interrompem e modificam esses trajetos iniciais de significação pela produção, uma biografia das skins que se refere a uma vida social interligada a esses objetos de consumo em jogo. Desse modo, a trajetória do objeto skin, uma fase da vida social que possui, não está apenas associada à sua condição de mercadoria, mas sobretudo a uma complexa rede de significados e interpretações que são dados por jogadores, comunidades de fãs e grupos sociais ao longo da existência de cada uma dessas mercadorias. Ao usar um desses objetos, uma teia de significados é diretamente associada e envolve também cobranças aos jogadores que os portam.

É preciso, portanto, considerar uma série de expectativas que pertencem à autonomia desses objetos em jogo (MACEDO e CORRAL VIEIRA, 2017) e, assim, os jogadores percebem que podem atuar sobre esses significados, reinterpretando a relação. Por sua vez, essas acepções fornecem aos sujeitos uma percepção ou um sentido do que os demais esperarão deles ao estarem de posse dos referidos objetos. Eles "objetificam”. Destarte, a não compatibilidade com determinadas expectativas gera sanções que podem oprimir os sujeitos, como evidenciado na fala de Jinx: "quando tu entra com skin as pessoas já esperam que tu jogue muito com aquele personagem, porque tu gastou teu dinheiro com ele e as pessoas acham que podem mandar na tua carteira”. Porém, de antemão, advertimos que um maior detalhamento dessa questão escaparia ao escopo da discussão que se pretende neste artigo. 
O que se evidencia, ao menos preliminarmente durante o early game, é uma relação de cultivo à reputação, à perícia, ao domínio técnico de um objeto (personagem), intimamente ligado e legitimado com o uso das skins (cf. MACEDO e CORRAL VIEIRA, 2017). A fala de Jinx trata de assinalar que a "fama" de jogadores em LoL, suas hierarquias e reputações em partidas (sobretudo) em um nível amador é intimamente relacionada com os objetos que usam, embora subsista uma competência e habilidade técnico-operacional - necessariamente inerente ao status de pro, dos jogadores exímios, por vezes profissionais (FALCÃO, 2014) - capaz de suplantar esse status provisório emanado pelas skins durante outros momentos do jogo (mid game e late game, por exemplo) nos quais prevalece a perícia técnica de cada jogador - no final, trata-se realmente do que importa e define partidas em um jogo agonístico como LoL.

No entanto, "as pessoas atuam sobre (e são representadas ou simbolizadas por) coisas" (MILLER, 2013, p. 104) e pelas “auras" que elas possuem. Logo, esses objetos, como bens de consumo investidos por uma dimensão simbólica, marcam a fronteira entre sujeitos que possuem e não possuem skins, delimitam as posições preliminares (em um nível bastante inicial do jogo e, ao menos, para amadores) de cada um no ambiente de LoL e reafirmam modelos de subjetividades (LEAL, FREIRE FILHO e ROCHA, 2016), conferindo valores simbólicos específicos aos sujeitos que os possuem por conta da alta estima e significação atribuídas pelo coletivo de jogadores.

Ademais, objetos saltam para fora e para dentro, entram e saem, da esfera da mercantilização. Isso denota dizer que eles possuem "vidas sociais”, carreiras ou trajetórias que variam conforme as mudanças de seus significados para os consumidores durante determinado tempo e espaço (WOODWARD, 2007). Os objetos, em algum momento de suas "vidas", podem ser definidos principalmente pelas suas relações enquanto valor monetário mercantil (ou de troca), que os classifica como "mercadorias"; algum tempo após uma transação econômica, a partir das suas incorporações - ou subjetivações (MILLER, 2013) - em 
rituais, culturas ou mundos privados, conforme percepções pessoais ou relacionamentos, tornam-se "desmercantilizados", passam a ser "bens" agregados de significados.

As skins podem, ainda, ser "remercantilizadas", reintroduzidas no mercado - quando algumas skins específicas são postas uma vez mais à venda pela empresa ou quando jogadores vendem suas contas em um mercado informal e considerado ilegal pela desenvolvedora. Expostas na loja, seja ela qual for, são mercadorias, mas, ao serem adquiridas, são novamente "desmercantilizadas" para dar lugar aos valores e subjetivações de cada sujeito. Potencialmente, as skins podem ser reinseridas no mercado para revenda em algum momento. "O ponto geral é este: objetos nunca são culturalmente fixos, mas sempre estão em processo de ser e tornar-se" (WOODWARD, 2007, p. 103). Por meio dessas transformações, cria-se um tipo similar e singular de biografia, em que os objetos, e não somente as pessoas, têm uma vida social.

Portanto, partindo das contribuições de Featherstone (1995), podemos pensar em um duplo aspecto simbólico de bens virtuais em jogos digitais como LoL: (i) de um lado, há uma carga de simbolismo presente no design e no imaginário introduzidos nos processos de marketing e de produção de itens como as skins; (ii) de outro, há uma diversidade de associações simbólicas utilizadas e renegociadas para destacar diferenças de estilos de vida, influenciando, mesmo que em um nível assaz superficial e não definido, as relações sociais nas partidas.

Similarmente, Rocha, Barros e Karam (2014) argumentam que o consumo tem duas dimensões na sociedade contemporânea: de um lado, instaura-se uma materialidade e, de outro, significação. Ao se adquirir uma mercadoria, alegam os autores, a sua materialidade é revestida em simbolismo, no qual cada produto tem um significado cultural e público sustentado por meio de narrativas midiáticas e publicitárias. Nas sociedades de consumo, os objetos digitais são distribuídos em larga escala, encontrados e usados por sujeitos que precisam negociar e estabelecer percepções próprias ao incorporá-las em suas práticas. 
Nessa perspectiva, podemos perceber como bens virtuais passam a configurar uma forma de aquisição de experiências de entretenimento. Para Draven, a posse de todos os bens relacionados à personagem Diana (Figura 5), com a qual tem uma relação afetiva intensa, não é mais suficiente. Ele, então, investiu "um dinheiro bom", como nos disse, para materializar o imaterial a partir de uma tatuagem - um símbolo lunar cravado na testa da personagem - mantida em segredo dos seus pais.

Figura 5: Ilustração oficial da personagem Diana.

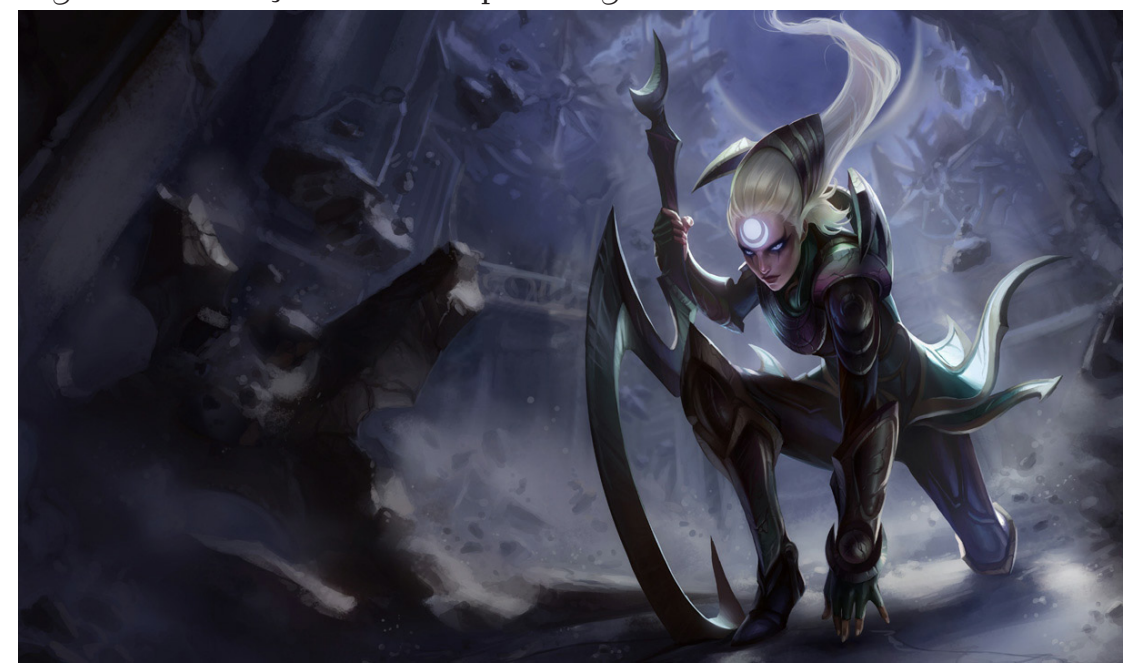

Fonte: Print screen da página da personagem Diana. Disponível em: https://goo.gl/HNiRdQ. Acesso em: 1 abr. 2017.

Draven nos diz: "em relação à tatuagem que eu fiz, é bem assim, eu fiz ela bem no meio das costas aqui [...], e fiz essa tatuagem porque tem um significado pra mim". Quando questionado sobre o porquê de tê-la feito e o significado que ela tinha, ele nos afirmou que gostava do nome da personagem. Em uma conversa com sua mãe, ele comentou que gostaria de ter uma filha chamada Diana, descobrindo que este era um desejo também de seus pais. Ele complementa: "a história dela [da Diana] [...] é diferente do que a vila dela era, do que o lar dela era, então 
eu também, às vezes, me acho muito diferente de muitas pessoas que eu vejo por aî".

A tatuagem expressa a imaterialidade pela materialidade: o ato de tatuar a personagem nas costas pode ser entendido pela necessidade de tornar material o desejo de Draven, apoiado no potencial de a tatuagem criar o legado da imaterialidade da personagem e suas skins como presença material em nosso mundo pelas vias do seu corpo. Assim, reconhecemos a materialidade irredutível presente nos processos de consumo - "não podemos escapar que a maioria das formas de consumo envolvem uma relação com as coisas materiais" (WOODWARD, 2007, p. 101). Isso evidencia, portanto, que a busca pelo material, por meio das experiências proporcionadas pelo imaterial, provoca ainda mais materialização (MILLER, 2013). Quanto mais bem-sucedida é sua afirmação, mais a Diana e suas skins acumulam e agregam em valores e significados para Draven.

As experiências de consumo e a cultura material desses objetos (personagens e skins, por exemplo) demonstram como as relações entre eles e os sujeitos passam a ser sui generis e contextualizadas a cada experiência e emoção e fundamentadas no sentido das vivências que deles decorrem, na importância que os objetos podem ter tanto nas vidas como nas percepções de mundo dos próprios jogadores.

\section{Considerações finais}

O consumo de objetos em League of Legends evidencia uma rede interconectada em um universo de significados construídos por jogadores que dão uma outra vida, "colonizam" e são influenciados por esses objetos na medida em que ambos se movimentam pelas paisagens sociais do jogo - por essa ambiência que os habitua e incita. Por meio de um estudo etnográfico, procuramos demonstrar as diversas capacidades que objetos em jogo, com especial atenção para o papel essencial das skins, têm para dar significado, construir um sistema social e simbólico.

Assim, o que podemos depreender é que a natureza do consumo de objetos em League fundamenta-se, para os jogadores, pelo envolvimento 
deles na transformação do significado e natureza desses itens. Trata-se de um esforço hermenêutico dos sujeitos em negar o valor de troca para que possam investir significados pessoais a esses objetos em jogo. Como consequência, as percepções são adaptáveis compreensões dos jogadores, que evidentemente não surgem ex nihilo, mas conforme categorias como posições/hierarquias sociais, idades, gêneros, domínio e perícia (habilidades e competências) acerca dos aspectos técnico-operacionais etc.

Em termos de investimentos, podemos destacar que, ao decidir entrar em LoL, um jogador acaba, em um grau mais visível, investindo seu tempo, dando atenção ao jogo e convertendo sua experiência no ambiente por recompensas, espólios de guerras, que são trocadas para o consumo de itens. A economia do jogo, assim, pode configurar-se também como escambo digital. Em LoL, todos são suscetíveis ao consumo em diferentes níveis, tanto pelo gasto do tempo para alcançar conquistas e trocar por itens quanto pela troca de dinheiro por moedas virtuais.

Mas o consumo sustenta-se, segundo Rocha (2000), por intermédio de códigos culturais que dão sentidos ao processo de produção a partir de relações com a cultura material e a mídia. Nesse sentido, consumo é percebido como fato social que envolve uma dimensão simbólica, com significações atreladas a códigos geradores de categorias como utilidade, desejo ou necessidade, que não se limitam à razão prática. Por mais que em um cenário estejam postos todos os elementos essenciais para a lógica do mercado, do jogo econômico da produção elencados por Rocha (2000), a ausência da ordem simbólica (e todas as suas nuances) impossibilita o acontecimento concreto do ato de consumir. Parece que não faltam, em League, códigos, sistemas simbólicos para completar os objetos ao lhes atribuírem usos e razões repletos de classificações aptas a cederem sentidos às mercadorias que se transformam em bens.

Os atos de consumo dos sujeitos em jogo chamam atenção e comunicam as escolhas, os modos como eles se organizam e dão sentido aos seus espaços nessa ambiência. Assim, pensar no consumo e no entretenimento denota o quanto são passíveis de se misturarem, seja no plano 
prosaico de uma partida em um jogo como LoL, seja pelas complexas dinâmicas que constituem representações coletivas, imaginários, aspectos competitivos imanentes a esse contexto e relações sociais per se.

Longe de esgotarmos o tema, uma vez que reconhecemos as lacunas que certamente figuram neste artigo, decorrentes do modo como endereçamos a nossa arguição, compreender este cenário é um desafio a ser desvelado por trabalhos futuros - o que se coloca como ofício a seguir. Investigar como essas relações sociais continuarão se delineando reivindica uma observação profunda em torno de questões acerca das dinâmicas e interfaces de entretenimento, consumo e jogos digitais, sabendo reconhecer a relevância e o lugar que conquistaram na nossa cultura, subsistindo neles uma trama social em que são tecidos significados variados e intensos capazes de ativarem questões tão complexas quanto outros fenômenos evidentes na cultura contemporânea.

\section{Referências}

AARSETH, E. O Jogo da Investigação: abordagens metodológicas à análise de jogos. Caleidoscópio: Revista de Comunicação e Cultura, Lisboa, n. 4, p. 9-23, 2003.

CASTRO, G. Comunicação e consumo nas dinâmicas culturais do mundo globalizado. Revista Pragmatizes, Niterói, n. 6, p. 58-71, 2014.

FALCÃO, T. Não Humanos em Jogo: agência e prescrição em World of Warcraft. 2014. 332f. Tese (doutorado em Comunicação e Cultura Contemporâneas) - Faculdade de Comunicação, Universidade Federal da Bahia, Salvador, 2014.

FEATHERSTONE, M. Cultura de consumo e pós-modernismo. São Paulo: Nobel, 1995. FRIELING, J. Virtual goods in online worlds: basics, characteristics and monetization. [s. 1.], 2013. Disponível em: https://goo.gl/NcMtzk. Acesso em: jul. 2016.

GELL, A. The technology of enchantment and the enchantment of technology. Oxford: Clarendon Press, 1992.

LEAL, T.; FREIRE FILHO, J.; ROCHA, E. Torches of freedom: mulheres, cigarros e consumo. Comunicação, Mídia e Consumo, São Paulo, v. 13, n. 38, p. 48-72, set.-dez. 2016. 
MACEDO, T.; AMARAL FILHO, O. Dos rios à tela de cristal líquido: o retorno do mito e a arquitetura da cultura convergente em League of Legends. Revista Fronteiras: estudos midiáticos, São Leopoldo, v. 17, n. 2, p. 231-247, maio-ago. 2015.

MACEDO, T.; CORRAL VIEIRA, M. Mais do que apenas dedos rápidos: narrativas e experiências de performances em League of Legends. Lumina, Juiz de Fora, v. 11, n. 1, p. 1-20, jan.-abr. 2017.

MARTIN, J. Consuming Code: Use-Value, Exchange-Value, and the Role of Virtual Goods in Second Life. Journal of Virtual Worlds Research, Austin, v. 1, n. 2, p. 1-21, 2008.

MILLER, D. Consumo como cultura material. Horizontes Antropológicos, Porto Alegre, ano 13, n. 28, p. 33-63, jul.-dez. 2007.

. Trecos, troços e coisas: estudos antropológicos sobre a cultura material. Rio de Janeiro: Zahar, 2013.

MILLER, D.; SLATER, D. Etnografia on e off-line: cibercafés em Trinidad. Horizontes Antropológicos, Porto Alegre, ano 10, n. 21, p. 41-65, jan.-jun. 2004.

REBS, R. Bens virtuais em social games. Revista Intercom, São Paulo, v. 35, n. 2, p. 205-224, 2012.

ROCHA, E. Totem e consumo: um estudo antropológico de anúncios publicitários. Alceu, Rio de Janeiro, v. 1, n. 1, p. 18-37, jul.-dez. 2000.

.; BARROS, C.; KARAM, K. Diversões perigosas: experiências de entretenimento e limites do consumo. In: ROCHA, E.; PEREIRA, C.; BARROS, C. (Orgs.). Cultura e experiência midiática. Rio de Janeiro: Mauad X: PUC-Rio, 2014.

SALEN, K.; ZIMMERMAN, E. Rules of Play: Game Design Fundamentals. Cambridge: MIT Press, 2003.

WOODWARD, I. Understanding Material Culture. Londres: Sage, 2007.

\section{Sobre os autores}

Tarcízio Macedo - Mestrando em Ciências da Comunicação pelo Programa de Pós-Graduação Comunicação, Cultura e Amazônia da Universidade Federal do Pará (PPGCom/UFPA), com bolsa Capes e período sanduíche no Programa de Pós-Graduação em Comunicação e Cultura Contemporâneas da Universidade Federal da Bahia (Póscom/UFBA) e no Centro de Pesquisa e Desenvolvimento de Jogos Digitais da Universidade do Estado da Bahia (CV/ Uneb). Pós-graduando em Comunicação Científica na Amazônia pelo Núcleo de Altos Estudos Amazônicos (Naea, UFPA). Membro do Grupo de Pesquisa Comunicação, Consumo e Identidade (UFPA/CNPq). 
Manuela do Corral Vieira - Doutora em Antropologia pela Universidade Federal do Pará (PPGA/UFPA). Mestre em Marketing pela Universidad Autónoma de Madrid (AAM). Professora da Faculdade de Comunicação e do Programa de Pós-Graduação Comunicação, Cultura e Amazônia da UFPA, ambos ligados ao Instituto de Letras e Comunicação da UFPA. Líder do Grupo de Pesquisa Comunicação, Consumo e Identidade (UFPA/CNPq).

Data de submissão: 13/04/2017

Data de aceite: 15/08/2017 